

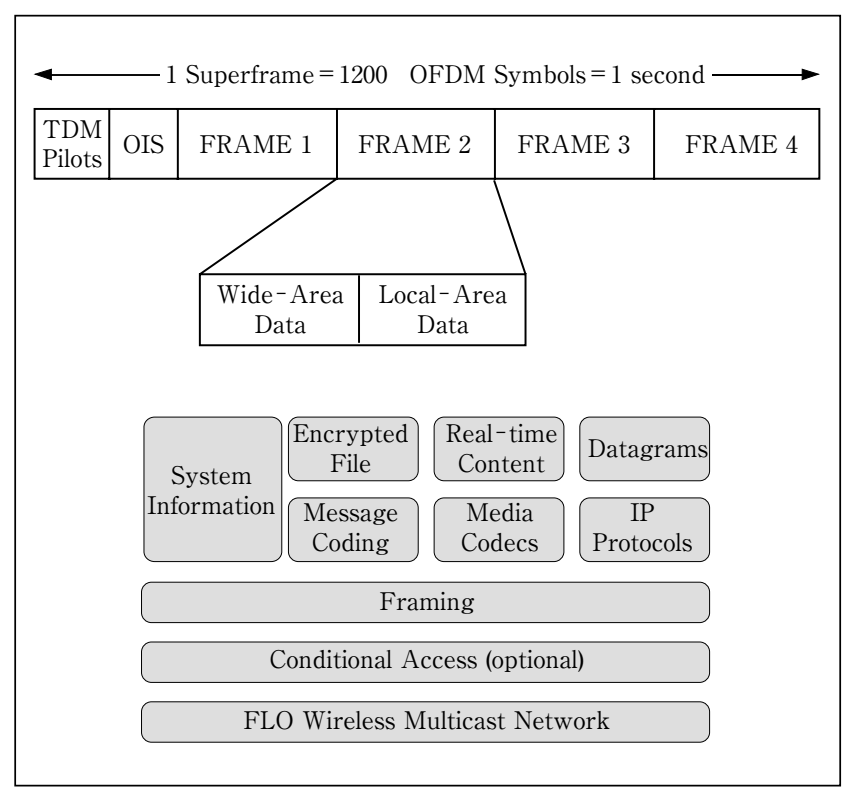

図 1 FLOフレーム構造とプロトコルスタック

OFDM Symbolsで伝送する.

また，MediaFLOでは映像や音声のようなメディアコン テンツの伝送とIPデータの伝送の両方をサポートする。 そ れぞれを最大効率で伝送するために, FLOではこれらを伝 送するプロトコルをそれぞれ直接Framing Protocol上に展 開する構造をとる。これは, IPネットワーク上でメディア コンテンッをMPEGで伝送したり, 逆に放送用ネットワー ク上でIPデータを伝送する場合に発生する, プロトコル機 能の重複による非効率を避けるためである。これらの映像 デー夕領域とIPデータ領域の容量の割当は, サービス内容 によりダイナミックに変更できるようになっている.

多チャネルサービスへの対応は, 一つのRFチャネル $(6 \mathrm{MHz})$ 内で複数の論理チャネルを扱えるようにすること でサポートする。この論理チャネルは, それぞれ異なった コーディングレートと変調方式を適用することが可能で, サービス内容, コンテンッ内容に応じた設定がなされる. この際, 受信端末は視聴する番組が送られてくる論理チャ ネルのみ受信すればよい構造になっており，これにより受 信時の消費電力の低減化を図っている．また，広域サービ スと地域サービスを同時にサポートするメカニズムも組込 まれ，放送サービスの要件として一般的な，地域限定サー ビスや，逆にある地域では放送しないBlack Outなどの機 能を提供する.

このFLOの技術は, クアルコムが独自開発したものであ るが，世界的普及を目指し，標準化を推進する団体FLO Forumが設立され, FLO Forumより, 米国TIA (Telecommunication Industry Assosiation) への標準化提 案もなされており, その仕様は TIA-1099として公表され る予定である。

\section{2 コンテンツ配信システム}

MediaFLOにおいては，映像や音声のストリーミング放 送とともに，蓄積型クリップの配信やIPデータの配信を行 う．FLOネットワークで配信されるこれらのデー夕はすべ て暗号化されており，その信号を受信するだけでは番組を 再生することはできない. 番組再生に必要な暗号鍵の取得 や，有料番組の場合の課金情報などのやり取りは, FLOネ ットワークではなく, 双方向通信が可能な携帯電話ネット ワークを利用して行われる。

このようなストリーミングコンテンツの送出と, クリッ プキャスティングコンテンツのスケジュール管理, 送出, そして受信, 加入者管理, 課金処理などを行うコンテンツ 配信システムが，ネットワーク側サーバ群と端末側クライ アントアプリケーションの間で構築される。これをMDS (Mdeia Distribution System) と呼ぶ.

MDSの主要サーバは, Distribution Server, License Key Server，およびSubsctiption Serverなどである。まずユー ザがサービスに加入する場合, ユーザの携带端末は携帯ネ ットワークを通じて, Subscription Serverと通信を行い, サービスへの加入が処理される. その上で, 暗号化された コンテンツ内容を再生するためのライセンス鍵をLicense Serverより取得する。一方，FLOネットワークに対して提 供されるコンテンツは暗号化され, Distribution Serverに よりFLOネットワークを通して端末に配信される。携帯端 末では, あらかじめ通信により取得されているライセンス 鍵を用いてコンテンツが再生されることになる.

\subsection{MediaFLOネットワーク}

図2にMediaFLOのネットワーク構成を示す。

National Operation Center (NOC) からは全国 (WideArea）を対象にしたコンテンツがまず各地のLocal Operation Center (LOC) に送られる. LOCではさらに各地 域の地域コンテンツを付加した上で，それを放送タワーや 山の上などに設置された放送アンテナに送り，そこから携 带端末に向けて電波が送出されることになる。

\section{MediaFLOのサービスイメージ}

MediaFLOでは, $6 \mathrm{MHz}$ の帯域幅で平均6Mbpsの伝送容 量を実現することができる.

映像サービスはQVGAの画面サイズで30fpsの映像提供を 基本としており，これに音声帯域を加えて，1チャネルあた り約350kbpsの伝送帯域が必要になる。このようなストリ ーミングチャネルを15チャネル以上提供する.ささらに, 残 りのキャパシティを利用して, あらかじめ10分とか 20 分の コンテンツを端末にダウンロードしておき, ユーザが都合 の良い時に(例えば，電波が届かない地下鉄など) その視聴 が可能となるクリップキャストサービスを行う．この方式 は, ネットワークの利用効率向上の観点から非常に有効で, 例えば早朝の時間帯など, 通常のストリーミングサービス 


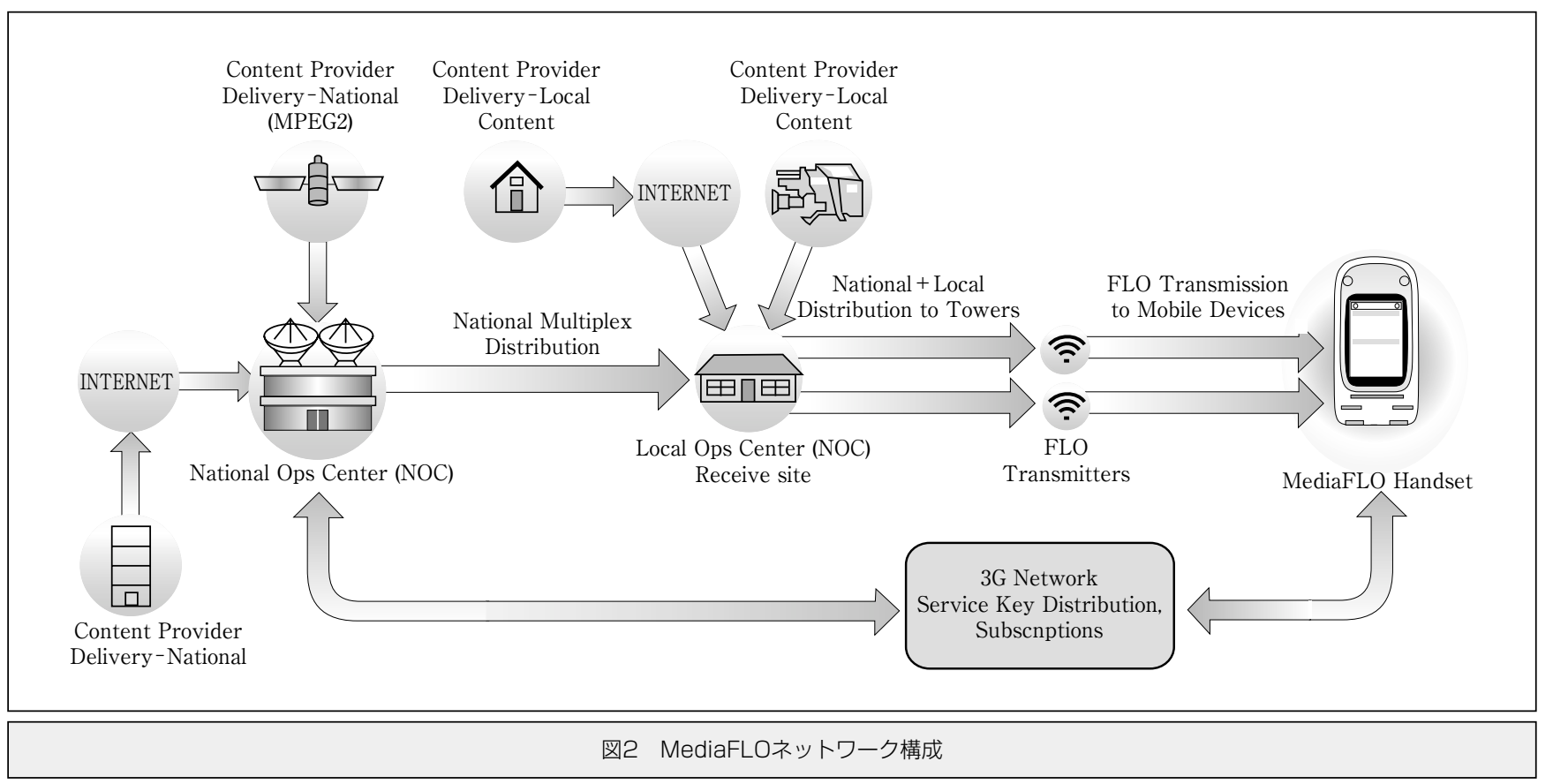

が休止している時間帯を使って, クリップキャスティング のコンテンツダウンロードを行うことなども可能になる.

当初はストリーミングビデオ放送15チャネル程度とストリ ーミングオーデイオ放送10チャネル程度, 蓄積型クリップキ ヤスト40チャネルを組合せたサービスが計画されている.

これらの番組のラインアップと番組の予定 (クリップキ ヤストの場合は次のアップデイト)の情報を含む, いわゆ るEPG (Electric Program Guide) も提供される。ユーザは 携帯電話のデイスプレイに表示されるEPGを見ながら視聴 する番組を選ぶことになる。

また，MediaFLOではいわゆる映像や音声のコンテンツ だけでなく, デー夕放送, データダウンロードも効率よく 扱える柔軟なシステムとなっている，地震などの緊急事態 発生時のアラート機能や, 株価などリアルタイムで変化す る情報のデータ放送サービス, さらに例えば自動車分野に おける車載システムへの最新地図データのダウンロードや 交通情報の放送など，多彩なサービスが考えられる。これ らの将来のサービス拡張の可能性をもつことはMediaFLO の大きな特徵の一つでもある.

\section{「米国のサービス計画および日本その他の地 域での展開}

米国に扔いては，このMediaFLOの技術開発を進めてい るクアルコムによりサービス提供会社MediaFLO USA Inc.が設立され，2006年10月のサービス開始を目指して， ネットワークの構築と端末の開発が進んでいる．使用する 周波数は, $716 \sim 722 \mathrm{MHz}$ という日本ではUHF 54 チャネル に相当する带域である。この周波数は米国では新規技術を 使った新サービスに利用可能な帯域として入札にかけら
れ，クアルコムがMediaFLOを展開するために落札した。 またクアルコムではMediaFLO受信機能を携帯電話端末に 搭載するためのASICをすでに開発済みで，それを使った 携帯電話がすでに開発されている。このようなクアルコム の開発を踏まえ, 米国最大の 5,000 万人のユーザを抱える携 帯電話キャリヤ, ベライゾンワイヤレスはMediaFLOサー ビスを2006年10月より提供することを表明している.

また日本においては，MediaFLOの2007年開始を目指し， 周波数の確保と事業計画の策定を行うメディアフロージャ パン企画が, 携帯電話事業を行っているKDDIとクアルコ ムジャパンの合弁会社として設立された。

このほか欧州やアジア地域でも, MediaFLOは携带電話 への将来の有望なサービスとして注目されており, 同様の 進展が今後見込まれる。

\section{5 亿むすび}

日々進化し続ける携带電話の次の有力なサービスとして, 放送サービスは世界中で期待が高まっている，米国を皮切 りに2006年秋より商用サービスが開始されるMediaFLOは, 日本をはじめ世界での普及が期待されており，その概略を 紹介した。

(2006年1月25日受付)

\section{〔文 献〕}

1) MediaFLO, http://www.qualcomm.com/mediaflo/

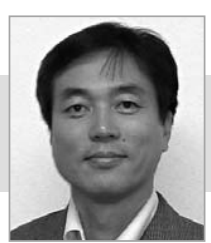

腈前忘苗 修作 1986年, 大阪大学工学部通信工学 科卒業. 同年, 伊藤忠商事 (株) 入社. 主に, 衛星 関連事業に従事. 1999年，クアルコムジャパン（株） 入社. CDMA2000関連技術の日本導入および新規事 業開拓を担当.

(67) 727 